\title{
A IMPORTÂNCIA DO REGIME ADUANEIRO DE DRAWBACK PARA INTERNACIONALIZAÇÃO DE EMPRESAS BRASILEIRAS
}

\author{
Christiane Nery Silva Pirett ${ }^{1}$, Cely Cristiane Nery Silva Pirett, Luciana Oranges Cezarino \\ Universidade Federal de Uberlândia, Minas Gerais, (Brasil)
}

\section{DETALHES DO ARTIGO}

\section{Artigo Convidado:}

Recebido: 21 de abril de 2018

Aceito: 10 de setembro de 2018

Disponível online: 01 de janeiro de 2019

\section{Editor Científico}

Ilan Avrichir

\section{Palavras-chaves:}

Regime Aduaneiro de Drawback

Globalização

Exportação

Internacionalização de Empresas

\section{RESUMO}

Objetivou-se buscar evidências a respeito dos aspectos positivos e negativos que têm conduzido empresas brasileiras a instituir, ou não, o regime aduaneiro de Drawback. Trata-se de Revisão Integrativa da literatura, com análise sistemática de conteúdo, realizada entre março-abril/2017. Foram incluídos estudos primários, publicados entre 2005-2017, on-line e na íntegra, e dados do portal da Secretaria de Comércio Exterior do Ministério do Desenvolvimento e Indústria e Comércio. Os resultados mostraram que apesar de o Drawback, efetivamente, reduzir a carga tributária dos insumos de exportação, não houve crescimento das taxas de uso do regime em relação às exportações totais brasileiras nos últimos anos. Mesmo entre as usuárias do Drawback, grande parte das empresas exportou com alto índice de nacionalização, sem os benefícios do regime. Principalmente devido ao excesso de burocracia do sistema aduaneiro e à carência de pessoal capacitado para a sua operacionalização, os benefícios do Drawback, apesar de relevantes - como redução de custos, expansão de mercados externos e melhoria da eficiência produtiva - não estimularam uma parcela significativa de empresas brasileiras à sua adesão. São necessários, portanto, investimentos políticos de incentivo ao comércio internacional, como capacitação gerencial para a sua operação, com o intuito de estimular empresas brasileiras a adotarem o regime de Drawback.

\section{INTRODUÇÃO}

Com a globalização, a superação das barreiras comerciais tornou-se uma das grandes preocupações na redução dos custos de exportação e importação pelas empresas, as quais precisam encontrar diferentes formas de competir, buscar inovação e aprimorar seus produtos. Nesse contexto, o Drawback se insere como um importante degrau à internacionalização dessas empresas no mercado externo, pela aquisição de benefícios do governo de incentivo à exportação.

Os regimes aduaneiros especiais, como o Drawback, distinguem-se dos comuns de importação e exportação, pela concessão de incentivos fiscais respectivos aos impostos incidentes no comércio exterior. São diferenciados por concederem

\footnotetext{
${ }^{1}$ Contato do autor E-mail: chris.nery@gmail.com

suspensão, isenção ou restituição de tributos aos importadores e exportadores. Tais incentivos demandam maior controle aduaneiro, diferentemente do comum que possui um trâmite normal quanto ao pagamento, às imunidades e às isenções, por não estarem sujeitos à condições e controles especiais da aduana (Ikeda, 2016; Folloni, 2005).

Nesse contexto, o Drawback apresenta-se como um instrumento da política de comércio exterior, pois permite a desoneração da carga tributária da cadeia produtiva na exportação de produtos (Silva, 2014). Ele é mundialmente utilizado em diversos países e existe no Brasil desde 1934, porém foi revogado em 1957 e é gerido, atualmente, pelo Decreto de Lei no 37, de 21/11/1966 (Araújo \& Sartori, 2003). 
De acordo com Cuba, Coti-Zelati e Araújo (2014), o principal objetivo do Drawback é incentivar as exportações, pois, eliminando-se a cobrança de impostos nas importações de matérias-primas, o produto final torna-se mais barato e passa a oferecer maior vantagem competitiva no exterior. Com isso, a tendência é aumentar a participação de empresas brasileiras no comércio internacional. Desse modo, este estudo objetivou apresentar evidências científicas acerca da importância do regime aduaneiro de Drawback, bem como dos aspectos positivos e negativos que têm conduzido empresas brasileiras a instituí-lo, ou não, como um mecanismo de redução de custos nas exportações e de favorecimento à internacionalização dessas empresas.

\section{REFERENCIAL TEÓRICO}

Instituído pelo Decreto de Lei no 37, de 18 de novembro de 1966, que dispõe sobre o Imposto de Importação, o Drawback permite desonerar tributos de importação, desde que pactuado ao compromisso de exportação (Decreto-Lei n. 37, 1966). Com as alterações na legislação e o avanço tecnológico da informação, chegou-se ao atual modelo de Drawback Integrado, que permite não só a desoneração de tributos para a aquisição de insumos importados, mas também para aqueles adquiridos no mercado interno. São duas as modalidades de Drawback Integrado: Suspensão e Isenção. O Integrado Suspensão foi estabelecido em 25 de março de 2010 através da Lei no 11.945 de 2009 e o Integrado Isenção pela Lei no 12.350 de 2010 (Ministério do Desenvolvimento, Indústria e Comércio Exterior [MDIC], 2011).

O Drawback é hoje um dos principais e mais efetivos mecanismos de desoneração tributária das exportações, possibilitando maior vantagem competitiva para empresas nacionais no mercado externo. Esse regime aduaneiro pode ser aplicado nas três modalidades definidas de acordo com o Decretolei $n^{\circ}$ 37, de 1966, art. 78, a Lei $n^{\circ}$ 8.402, de 1992, art. $1^{\circ}$, inciso I e o Decreto no 6.759, de 2009: i) suspensão dos tributos de importação sobre insumos a serem exportados após seu beneficiamento ou daqueles destinados à fabricação, complementação ou acondicionamento de outro produto a ser exportado; ii) isenção dos impostos de importação de insumos, em igual quantidade e qualidade àquela requerida para beneficiamento, fabricação, complementação ou acondicionamento de produto exportado; e iii) restituição, total/parcial, dos impostos pagos na importação de insumos exportados após beneficiamento ou usados na fabricação, complementação ou acondicionamento de outra mercadoria exportada (Barral \& Sá Barreto, 2010).

Com a entrada da Portaria Conjunta Secex/RFB no 1.460 de 2008, instituiu-se o Drawback Verdeamarelo, que permite aquisições no mercado interno de insumos para o manufaturamento de produtos destinados à exportação. Assim, foi possível a suspensão dos impostos IPI (Imposto Sobre Produtos Industrializados), PIS (Programa de Integração Social), PASEP (Programa de Formação do Patrimônio do Servidor Público) e COFINS (Contribuição para o Financiamento da Seguridade Social) para insumos provenientes do mercado interno. A redução desses impostos possibilitou o tratamento entre produto importado e nacional de forma igualitária (Barral \& Sá Barreto, 2010), incentivando empresas nacionais a expandirem seus negócios para o mercado externo.

O mercado internacional caracteriza-se por uma elevada competitividade, sobretudo, pelas mudanças advindas da globalização, a qual pode ser definida como processo de internacionalização das atividades capitalistas. Esse processo apresenta tendência elevada de redução ou, até mesmo, de supressão das barreiras alfandegárias e pode também levar à uma liberdade total quanto ao fluxo de capital entre os países (Guimarães, 2015).

Neste contexto, para se firmarem no mercado, é necessário que as empresas adotem estratégias, a exemplo do Drawback que Ihes propiciem vantagem competitiva sobre as demais. As estratégias internacionais precisam corresponder a dois preceitos mínimos, ou seja, explorar economias realmente acessíveis e que possam ser reflexos de outros investidores externos (Barney \& Hesterly, 2011).

O acesso a produtos, tecnologia e mão de obra baratos é imprescindível para uma firma conquistar o mercado internacional. Contudo, a redução do preço das matérias-primas é destacada como o maior incentivo para que empresas iniciem transações internacionais. A inserção no mercado internacional resulta não somente em aumento nas vendas, como também em redução nos custos (Barney \& Hesterly, 2011). Destarte, ressalta-se, a importância do Drawback na geração de vantagem competitiva para a internacionalização de empresas, na redução de 
custos e para facilitar seu ingresso no mercado estrangeiro (Cuba, Coti-Zelati \& Araújo, 2014).

Entretanto, no Brasil, a questão da logística dificulta a competição no mercado internacional somado a políticas públicas pouco efetivas adotadas pelo governo brasileiro nas últimas décadas. As deficiências são múltiplas, entre elas destacam-se a infraestrutura e o oneroso regime tributário. O fraco desenvolvimento do governo demonstra a pouca preocupação em elevar o país a um patamar de competitividade por custo, qualidade e produtividade (Freitas, 2004).

Outras desvantagens para o uso do Drawback, são: i) custos administrativos altos para o controle; ii) altas taxas de juros e o câmbio; iii) vagarosa burocracia do governo, incompatível com a velocidade das mudanças no comércio internacional; e iv) políticas públicas desiguais, como a falta de regulamentação específica a pequenas e médias empresas (Araújo \& Sartori, 2003).

\section{PROCEDIMENTOS METODOLÓGICOS}

Esta pesquisa trata-se de numa Revisão Integrativa da literatura, realizada conforme o método proposto por Mendes, Silveira e Galvão (2008), em seis etapas: i) identificação do tema, seleção da hipótese/questão de pesquisa; ii) eleição dos critérios de inclusão e exclusão, amostragens e busca na literatura; iii) definição dos dados a serem recuperados e categorização dos estudos; iv) avaliação de todos os estudos incluídos; v) análise dos resultados; e vi) apresentação da revisão e síntese do conhecimento.

O método da Revisão Integrativa permite vasta busca de pesquisas primárias na literatura, análise crítica e síntese do tema investigado. Dessa forma, seu resultado representa a situação atualizada do assunto, com potencial de permitir que diversos métodos de pesquisa se tornem uma parte maior das iniciativas da prática baseada em evidências (PBE) (Mendes, Silveira \& Galvão, 2008; Whittermore \& Knafl, 2005). Procurou-se responder às seguintes questões: qual é a importância do regime aduaneiro de Drawback para a prática da internacionalização de empresas situadas no território brasileiro e quais são os principais fatores que têm influenciado essas empresas a aderirem, ou não, a esse regime?
Os dados foram coletados entre março e julho de 2017. Foi realizada busca on-line nas seguintes bases: SciELO - Scientific Eletronic Libraty Online; ScienceDirect; JSTOR - Journal Storag; Web of Science; Oxford Journals; Nature (NPG - Nature Publishing Group), além de publicações do portal da Secretaria de Comércio Exterior do Ministério do desenvolvimento e Indústria e Comércio (SECEX/MDIC).

Foram utilizadas as seguintes palavras-chave e suas combinações nas línguas portuguesa, inglesa e espanhola: Regime Aduaneiro de Drawback, globalização, exportação e internacionalização de empresas.

Os artigos incluídos nesta RI foram: estudos primários, publicados em português, inglês ou espanhol, entre 2005-2017, disponibilizados em revistas on-line e na íntegra. Foram também utilizados dados consolidados do Drawback, disponibilizados on-line no Portal SixcomexRFB/SECEX. Foram excluídos: artigos de revisão, monografias, teses e pesquisas em idiomas diferentes do proposto ou fora do período estabelecido.

Após leitura minuciosa, crítica e reflexiva dos textos foi realizada avaliação sistemática das informações coletadas nos dez estudos selecionados. A análise sistemática do conteúdo foi feita pela comparação dos resultados semelhantes ou discordantes entre as pesquisas. Esses resultados foram discutidos com base nos artigos selecionados e demais publicações da área sobre o assunto.

A seguir foram elaboradas as inferências e as conclusões resultantes.

\section{RESULTADOS}

Através da busca nas bases de dados, encontrouse 20 artigos completos referentes ao tema, entretanto, após leitura do conteúdo, dez desses foram excluídos, por não se adequarem rigorosamente aos critérios preestabelecidos. Assim, dez artigos primários compuseram a amostra final desta revisão. A Figura 1 mostra o número de artigos avaliados, de acordo com o ano de publicação. Observa-se a distribuição desigual dos estudos no período pesquisado. Ressalta-se um longo período sem publicações (2007-2010). 


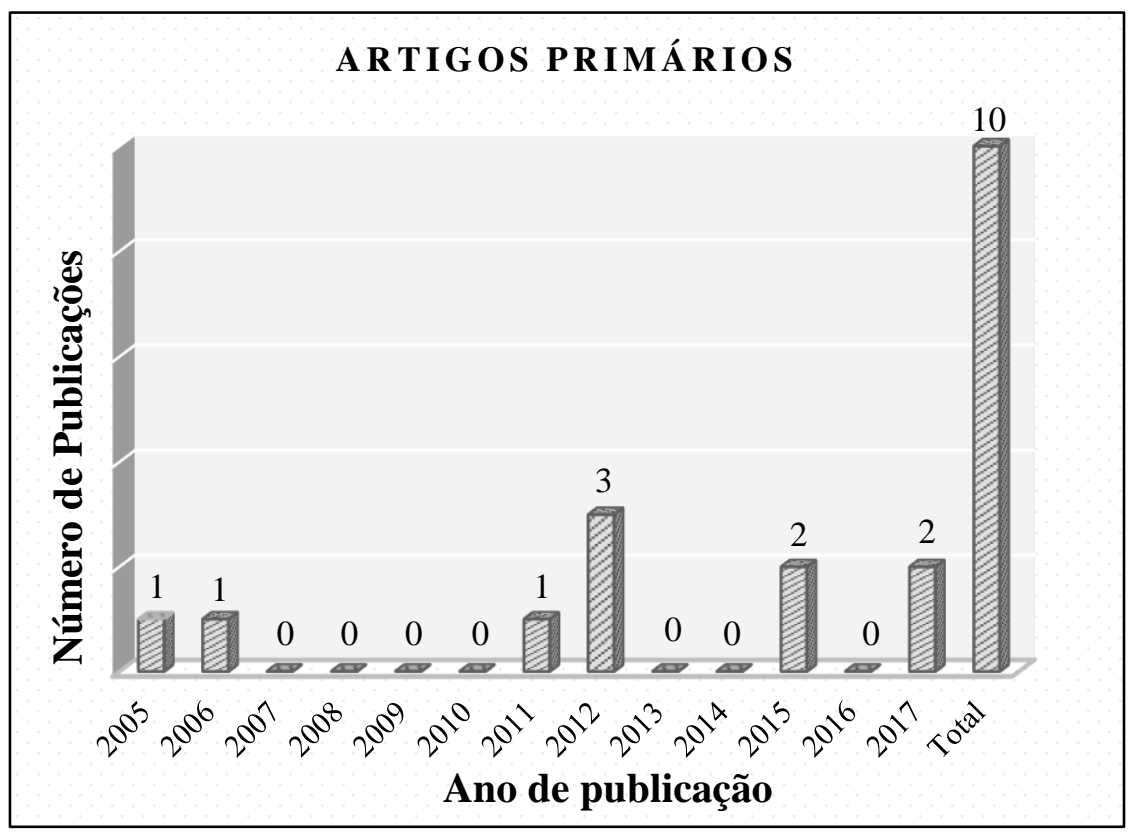

Fonte: Elaboração própria.

Quando comparados os dados do Portal Sixcomex relativos à participação do Drawback nas exportações brasileiras nos últimos 12 anos, observou-se que entre 2005 a 2007, a porcentagem de uso do

\section{Tab. 1}

Participação das exportações brasileiras sob o regime de drawback sobre a exportação total (em
Drawback foi superior a $30 \%$ no total das exportações. Contudo, a partir de então observou-se um declínio e desde 2010, a participação do regime não ultrapassou os $25 \%$ (Tabela 1).

\begin{tabular}{c|c|c|c}
\hline \multirow{2}{*}{ Ano } & \multicolumn{2}{|c|}{ Exportação } & \multirow{2}{*}{ Porcentagem } \\
\cline { 2 - 4 } & Drawback & 118 & 30,5 \\
\hline 2005 & 36 & 137 & 32,8 \\
\hline 2006 & 45 & 160 & 31,2 \\
\hline 2007 & 50 & 197 & 28,4 \\
\hline 2008 & 56 & 152 & 24,3 \\
\hline 2009 & 37 & 201 & 24,8 \\
\hline 2010 & 50 & 256 & 23,0 \\
\hline 2011 & 59 & 242 & 22,3 \\
\hline 2012 & 54 & 242 & 21,1 \\
\hline 2013 & 51 & 225 & 23,5 \\
\hline 2014 & 53 & 191 & 24,6 \\
\hline 2015 & 47 & 185 & 2,7 \\
\hline 2016 & 42 & & \\
\hline
\end{tabular}

Fonte: Elaboração própria.

US\$ milhões) a partir de dados do Portal SixcomexRFB/SECEX. Uberlândia, MG, Brasil, 2018

Fonte: Elaboração própria. 
A Tabela 2 apresenta os artigos incluídos no resultado da presente revisão, de acordo com o nome dos autores, o ano de publicação, o título, a metodologia aplicada e o objetivo dos estudos. Os artigos foram inseridos na tabela em ordem decrescente quanto ao ano de publicação. Um deles foi publicado em periódico internacional, em inglês e os demais em português.

Quanto ao método, quatro estudos (40\%) tiveram delineamento transversal, descritivo e quantitativo. Os demais foram estudos de caso (três artigos), pesquisa de campo transversal descritiva (dois artigos) e um deles estudo de casos múltiplos. A maioria (60\%) das pesquisas utilizou dados de questionários que enviaram por meio eletrônico e foram respondidos por profissionais com cargos de gestão. Segundo os autores, a forma de envio on-line dos formulários da pesquisa foi um grande facilitador, pois permitiu agilidade e ampliação do leque de empresas. A metade dos estudos também realizou a coleta de dados documentais nas empresas avaliadas (Tabela 2).

Tab. 2

Organização dos artigos primários incluídos nos resultados da Revisão Integrativa conforme número

do artigo, autores, ano de publicação, título, metodologia e objetivo. Uberlândia, MG, Brasil, 2018

\begin{tabular}{|c|c|c|c|}
\hline $\begin{array}{c}\text { Autores } \\
\text { (Ano) }\end{array}$ & Título & Metodologia & Objetivo \\
\hline $\begin{array}{l}\text { Silva \& } \\
\text { Dalfior } \\
(2017)\end{array}$ & $\begin{array}{l}\text { - Drawback: estudo de } \\
\text { controles de utilização } \\
\text { em empresas de rochas } \\
\text { ornamentais no sul do } \\
\text { Estado do Espírito } \\
\text { Santo. }\end{array}$ & $\begin{array}{l}\text { - Estudo transversal, descritivo e quantitativo. } \\
\text { - Utilizado questionário fechado enfatizando se as empresas utilizavam } \\
\text { o Drawback, em qual modalidade, qual a forma de controle e quais as } \\
\text { suas exportações com o benefício do regime. }\end{array}$ & $\begin{array}{l}\text { - Analisar as operações com } \\
\text { Drawback nas empresas de } \\
\text { rochas ornamentais no sul do } \\
\text { Estado do Espírito Santo. }\end{array}$ \\
\hline $\begin{array}{l}\text { Bart \& } \\
\text { Dörr } \\
(2017)\end{array}$ & $\begin{array}{l}\text { - Estudo de caso nas } \\
\text { operações sob o regime } \\
\text { de Drawback em uma } \\
\text { empresa do município } \\
\text { de Igrejinhas/RS. }\end{array}$ & $\begin{array}{l}\text { - Estudo de caso de caráter qualitativo e quantitativo realizado em } \\
\text { indústria de calçados de grande porte do Vale do Paranhana/RS. } \\
\text { - Um dos colaboradores que respondeu ao questionário era o } \\
\text { responsável pelas exportações, o outro respondente pelas importações. } \\
\text { - Dados de documentos da empresa também foram coletados. }\end{array}$ & $\begin{array}{l}\text { - Identificar e analisar o processo } \\
\text { que a organização realiza nas } \\
\text { suas importações de insumos } \\
\text { para as exportações de calçados } \\
\text { sob o regime de drawback. }\end{array}$ \\
\hline $\begin{array}{l}\text { Dallacorte } \\
\text { \& Zeni } \\
(2015)\end{array}$ & $\begin{array}{l}\text { - Utilização do regime } \\
\text { Drawback como fator } \\
\text { competitivo no mercado } \\
\text { internacional. }\end{array}$ & $\begin{array}{l}\text { - Estudo de caso da empresa Cooperativa Aurora. Trabalho } \\
\text { fundamentado por pesquisa de campo e documentos da empresa. } \\
\text { - Empresa do ramo alimentício (frigorífico) do oeste do estado de Santa } \\
\text { Catarina. } \\
\text { - Identificaram-se os processos que a empresa realiza para atender o } \\
\text { regime de Drawback. }\end{array}$ & $\begin{array}{l}\text { - Demonstrar a utilização do } \\
\text { regime de Drawback como } \\
\text { fator competitivo no mercado } \\
\text { internacional. }\end{array}$ \\
\hline $\begin{array}{l}\text { Olivo et } \\
\text { al. (2015) }\end{array}$ & $\begin{array}{l}\text { - Logistics and special } \\
\text { customs regimes: The } \\
\text { uses of Drawback by } \\
\text { export companies in } \\
\text { southern Brazil. }\end{array}$ & $\begin{array}{l}\text { - Estudo transversal descritivo, de campo. } \\
\text { - População-alvo foram produtores exportadores do Sul de Santa } \\
\text { Catarina. } \\
\text { - Houve contato direto entre pesquisadores e profissionais de comércio } \\
\text { internacional das empresas que usam ou usaram o Drawback, a fim de } \\
\text { obter dados primários. }\end{array}$ & $\begin{array}{l}\text { - Analisar o uso do Drawback em } \\
\text { operações logísticas de } \\
\text { empresas exportadoras do } \\
\text { estado de Santa Catarina, no sul } \\
\text { do Brasil. }\end{array}$ \\
\hline $\begin{array}{l}\text { Art. } 5 \\
\text { Brito Jr. et } \\
\text { al. (2012) }\end{array}$ & $\begin{array}{l}\bullet \text { Um modelo de } \\
\text { localização e transbordo } \\
\text { multiproduto para } \\
\text { avaliação do impacto de } \\
\text { regimes aduaneiros. }\end{array}$ & $\begin{array}{l}\text { - Estudo transversal descritivo, de campo. } \\
\text { - Realizou-se comparação entre os custos logísticos do regime de } \\
\text { Drawback versus RECOF Aeronáutico e entre os modais de transporte } \\
\text { aéreo e marítimo. } \\
\text { - O estudo teve modelagem matemática através de programação linear } \\
\text { inteira mista. }\end{array}$ & $\begin{array}{l}\text { - Analisar o impacto dos regimes } \\
\text { aduaneiros na logística de } \\
\text { aquisição de materiais em } \\
\text { unidades fabris instaladas no } \\
\text { Brasil e no exterior, para uma } \\
\text { empresa fabricante de aviões } \\
\text { comerciais e militares. }\end{array}$ \\
\hline $\begin{array}{l}\text { Art. } 6 \\
\text { Moori et } \\
\text { al. (2012) }\end{array}$ & $\begin{array}{l}\text { - A influência do } \\
\text { Drawback nas } \\
\text { atividades logísticas em } \\
\text { empresas de bens de } \\
\text { capital mecânico. }\end{array}$ & $\begin{array}{l}\text { - Estudo transversal, descritivo e quantitativo. } \\
\text { - Utilizou-se questionário fechado. Comparou-se o desempenho das } \\
\text { atividades logísticas entre } 73 \text { MPEs e MGEs de bens de capital } \\
\text { mecânico. } \\
\text { - Utilizou-se a gestão da logística integrada como modelo conceitual } \\
\text { segundo a abordagem de Bowersox e Closs (2001). }\end{array}$ & $\begin{array}{l}\text { - Entender como os gestores } \\
\text { administravam o regime } \\
\text { aduaneiro do Drawback para a } \\
\text { obtenção da competitividade } \\
\text { internacional. }\end{array}$ \\
\hline $\begin{array}{l}\text { Moori, } \\
\text { Benedetti } \\
\& \text { Konda }\end{array}$ & $\begin{array}{l}\text { - O regime aduaneiro de } \\
\text { Drawback em operações } \\
\text { logísticas internacionais. }\end{array}$ & $\begin{array}{l}\text { - Estudo transversal, descritivo, quantitativo. } \\
\text { - Foram comparadas } 98 \text { empresas usuárias e } 38 \text { não usuárias do } \\
\text { Drawback. } \\
\text { - A coleta de dados foi por questionários fechados, enviados a uma } \\
\text { amostra de empresas. }\end{array}$ & $\begin{array}{l}\text { - Comparar as operações } \\
\text { logísticas de empresas que } \\
\text { utilizam e empresas que não }\end{array}$ \\
\hline
\end{tabular}


(2012)

\section{Art. 8}

Moori,

Konda \&

Gardesani (2011)
- A Associação Brasileira da Indústria de Máquinas e Equipamentos (ABIMAQ) disponibilizou o questionário em página eletrônica às empresas associadas, independentemente do porte da empresa. utilizam o regime de Drawback em suas transações.
-Estudo transversal, descritivo e quantitativo.

- Dados coletados em questionário semiestruturado, com 23 assertivas.

- Preencheram o questionário da pesquisa profissionais atuantes em 29 MPEs e 69 MGEs com cargos de gestão e experiência no regime de Drauback.

- Os questionários foram disponibilizados na página eletrônica da ABIMAQ às empresas associadas e em cursos de treinamento sobre Drawback de um centro de capacitação.

- Estudo de casos múltiplos, descritivo e transversal. Pesquisa • Analisar a influência do quantitativa e qualitativa, realizado com 15 empresas de móveis de São Bento do Sul/SC, usuárias do Drawback.

Art. 9 - Influência do Drawback no preço de exportação

Mayer \& do setor moveleiro de

Borba São Bento do Sul.

(2006)

- Foram coletados dados secundários através de pesquisa documental das empresas e dados primários através de pesquisa de campo com aplicação de questionário.

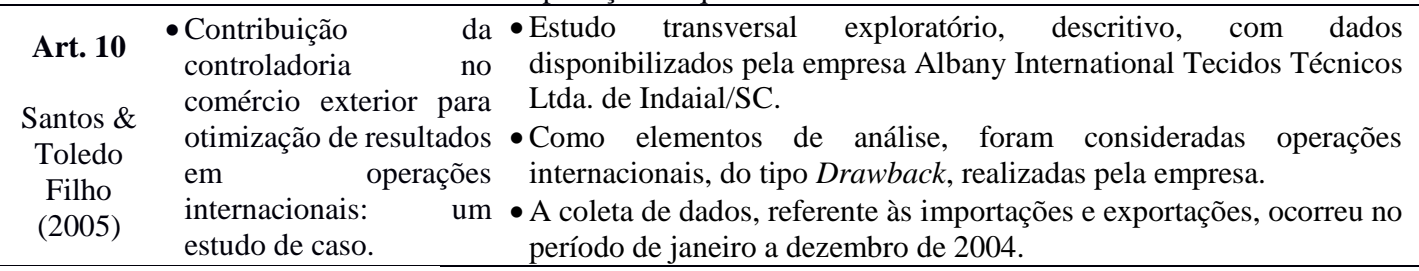

Fonte: Elaboração própria.

Os dez artigos da presente revisão analisaram 391 amostras de empresas brasileiras quanto ao uso do Drawback. 40\% dos estudos tiveram como amostra uma só empresa cada um (um caso). Já nos demais (seis estudos) a amostragem foi diversificada (15, 21, 44, 73, 98 e 136 empresas). As empresas eram de vários seguimentos, principalmente do setor de bens

de capital mecânico (três estudos). Nos demais estudos as empresas eram de rochas ornamentais, calçados, alimentos, aeronáutica, móveis de madeira e têxtil. Uma das pesquisas não identificou o tipo de produção. O resumo dos principais resultados desses estudos encontra-se na tabela 3.

\section{Tab. 3}

Principais resultados apontados nos estudos primários avaliados na Revisão Integrativa de acordo
- Comparar empresas de bens de capital de micro e pequeno porte e de médio e grande porte quanto ao uso do regime aduaneiro do Drawback. exportação, verificando se os benefícios provenientes do Drawback são repassados ao preço de exportação.

- Apresentar a contribuição da controladoria no comércio exterior para otimização de resultados em operações internacionais.

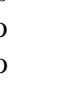




\begin{tabular}{|c|c|}
\hline $\begin{array}{l}\text { Brito Jr. et } \\
\text { al. (2012) }\end{array}$ & $\begin{array}{l}\text { - Amostra: Empresa fabricante de aviões sediada em Harbin (China). São José dos Campos no Brasil é um dos polos onde ocorre a } \\
\text { consolidação dos materiais enviados para abastecimento em Harbin. Tais materiais possuem restrições de lote mínimo de aquisição. } \\
\text { - Os custos do estoque são os maiores fatores que influenciaram no custo total, sendo maior em regime Drawback do que em Recof. } \\
\text { - O Recof Aeronáutico permitiu à empresa: redução de custos logísticos; vantagem competitiva pela redução dos ciclos logísticos e dos } \\
\text { lead times de abastecimentos; melhoria e flexibilidade nas linhas de produção e; maior capacidade de atendimento às necessidades dos } \\
\text { clientes. }\end{array}$ \\
\hline $\begin{array}{l}\text { Moori et } \\
\text { al. (2012) }\end{array}$ & $\begin{array}{l}\text { - Amostra: } 73 \text { empresas usuárias do Drawback, a maioria (79,5\%) na modalidade Suspensão e } 71,2 \% \text { era de São Paulo. } 23 \\
\text { corresponderam ao porte de MPE e } 68,5 \% \text { de MGE. } 50,7 \% \text { da amostra tinha mais de } 15 \text { anos de uso do Drawback. } \\
\text { - Houve baixo nível de internacionalização com poucos insumos importados. As vantagens do Drawback foram mais para MGEs que } \\
\text { introduziram mais eficientemente produtos novos no mercado do que as MPEs. } \\
\text { - Em sua maioria, nas importações o transporte foi marítimo }(67,1 \%) \text {, aéreo }(30,1 \%) \text { e multimodal }(2,8 \%) \text {. Já o embarque das exportações } \\
\text { foi mais distribuído: marítimo, } 31,8 \% \text {, aéreo } 40,9 \% \text {, rodoviário } 18,2 \% \text { e multimodal } 9,1 \% \text {. }\end{array}$ \\
\hline $\begin{array}{l}\text { Moori, } \\
\text { Benedetti } \\
\text { \& Konda } \\
(2012)\end{array}$ & $\begin{array}{l}\text { - Amostra: } 136 \text { empresas, a maioria }(76,5 \%) \text { de São Paulo. } 98 \text { (72,0\%) eram usuárias do Drawback, destas, } 94,9 \% \text { era do setor de bens } \\
\text { de capital e } 38 \text { (27\%) não eram usuárias do regime. } \\
\text { - } 26 \% \text { dos respondentes era da diretoria ou superior. A função principal foi operações de comércio exterior }(38,0 \%) \text {. Pequenas, médias e } \\
\text { grandes empresas representaram, cada uma, } 31,5 \% \text { e microempresas } 5,5 \% \text { do total. Das usuárias, houve predominância das MGEs. } \\
\text { - } 55 \% \text { das empresas tinha experiência de mais de } 10 \text { anos com exportação de seus produtos. A maior parte }(71 \%) \text { das empresas teve } \\
\text { menos de } 25 \% \text { do faturamento como resultado de suas exportações. } \\
\text { - O embarque das importações e exportações foi inferior a um mês para a maioria das empresas ( } 76 \% \text { e } 67 \% \text {, respectivamente). } \\
\text { - As principais desvantagens do Drawback foram a dificuldade de pessoal especializado, a complexidade e a necessidade de rígidos } \\
\text { controles fiscais. A não utilização do Drawback foi, principalmente, por falta de capacitação gerencial e de conhecimento do regime. }\end{array}$ \\
\hline $\begin{array}{l}\text { Moori, } \\
\text { Konda \& } \\
\text { Gardesani } \\
\text { (2011) }\end{array}$ & $\begin{array}{l}\text { - Amostra: } 98 \text { empresas (29 MPEs e } 69 \text { MGEs) usuárias do Drawack, a maioria do Estado de São Paulo (76,5\%) e as demais do Rio } \\
\text { Grande do Sul, Minas Gerais, Santa Catarina, Rio de Janeiro e Paraná. } 93 \text { empresas ( } 94,9 \%) \text { eram do setor de bens de capital. } \\
\text { - Houve baixo nível de internacionalização. O faturamento com exportação foi menor que } 25 \% \text { para } 65,3 \% \text { das empresas. Das exportações } \\
\text { com o Drawback, 63,3\% das firmas correspondia a menos que } 25 \% \text { e só } 2 \% \text { tinham entre } 96 \text { e } 100 \% \text { de uso do Drawback no total } \\
\text { exportado. } \\
\text { - Para as MPEs, a melhor qualidade dos produtos importados foi um dos grandes benefícios do uso do regime, já para as MGEs, o uso do } \\
\text { Drawback proporciona maior participação no mercado externo e oferta mais empregos. } \\
\text { - } 84,1 \% \text { concordaram que o Drawback atende às necessidades da empresa e os benefícios compensam os gastos com a operação. }\end{array}$ \\
\hline $\begin{array}{c}\text { Mayer \& } \\
\text { Borba } \\
(2006)\end{array}$ & $\begin{array}{l}\text { - Amostra: } 15 \text { indústrias do polo moveleiro de São Bento do Sul praticantes do Drawback. 53,3\% exclusivamente exportadoras. O } \\
\text { principal país de importação são os Estados Unidos e o principal produto importado é a cola. } \\
\text { - Quanto à modalidade, somente o Drawback Suspensão é conhecido por todas as empresas. A maioria delas não tem interesse em utilizar } \\
\text { outras modalidades e apenas uma utilizou a modalidade Isenção. } \\
\text { - Todas as empresas consideraram o Drawback uma vantagem competitiva no mercado internacional devido à redução de custos e da não } \\
\text { necessidade de pagamento dos impostos no ato da importação. }\end{array}$ \\
\hline
\end{tabular}
Fonte: Elaboração própria.

Diante da avaliação da Tabela 1, nota-se que, apesar do Drawback reduzir efetivamente a carga tributária dos insumos requeridos nos processos das empresas exportadoras, seu uso está aquém do satisfatório. Observou-se também que o Brasil apresentou notório crescimento, nos últimos 12 anos, quanto ao volume financeiro das exportações totais, contudo o mesmo não ocorreu quanto às exportações com o Drawback.

Análise crítica do conteúdo, houve a diferenciação de oito temáticas, as quais foram mais abordadas nos artigos da presente revisão. Os tópicos a seguir abordam os temas encontrados.

\section{O Contexto da Globalização no Processo de Internacionalização de Empresas no Brasil}

A abertura da maior parte dos mercados internacionais possibilita que empresas estrangeiras possam concorrer francamente com as nacionais em mercados locais, antes protegidos. Pequenas e médias empresas precisam avaliar sua expansão em operações internacionais, não somente quanto à exportação, mas também por meio de acordos de terceirização de determinadas atividades produtivas, que podem se dar através de alianças e contratos internacionais (Olivo et al., 2015).

Para competir com empresas nacionais e estrangeiras, as empresas brasileiras necessitam elevar o padrão de qualidade dos produtos sem, no entanto, elevar o preço final. Todavia, por dificuldades de adaptação a esse novo cenário, no decorrer dos anos, muitas dessas empresas fecharam 
as portas ou venderam as ações para concorrentes (Santos \& Toledo Filho, 2005).

Lançar mão de ferramentas como o Drawback é um dos recursos para melhorar os lucros e a competitividade das empresas pelo incentivo fiscal à exportação. Apesar disso, os resultados da presente revisão mostraram que, de acordo com os trabalhos de Moori et al. (2012) e Moori, Benedetti e Konda (2012) que avaliaram empresas de bens de capital mecânico, houve baixo nível de internacionalização desse seguimento com foco no mercado interno. Além disso, a maioria das empresas usuárias desse regime exportou parte de seus produtos com alto índice de nacionalização.

\section{O Drawback e as Políticas Públicas Econômicas de Incentivo}

Compete ao Estado a responsabilidade pela macropolítica de comércio exterior do país. Nesse sentido, o Estado tem a responsabilidade de promover condições mínimas ao desenvolvimento das empresas, sobretudo a questão imperativa ao comércio exterior, que é a prática de preços competitivos dos produtos para exportação (Mayer \& Borba, 2006).

No Brasil existem algumas ações envolvendo a participação de setores públicos e privados em vários segmentos, com 0 intuito de aumentar a competitividade das empresas exportadoras e de agregar mais valor aos produtos e serviços (Moori, Konda \& Gardesani, 2011). De acordo com Moori et al. (2012), entre os principais mecanismos de apoio à exportação no Brasil encontram-se: i) o Programa de Apoio Tecnológico à Exportação (PROGEX); ii) as parcerias entre o Instituto de Pesquisas Tecnológicas de São Paulo (IPT) e o Serviço Brasileiro de Apoio às Micros e Pequenas Empresas (SEBRAE) e; iii) o Exporta Fácil.

Os estudos de Moori, Konda e Gardesani (2011) e Moori, Benedetti e Konda (2012) apontam que a utilização do Drawback nem sempre tem sido lucrativa. Para empresas pequenas, a internacionalização envolve maiores dificuldades, como: i) desconhecimento e fragilidade da marca; ii) dificuldade de acesso aos canais de distribuição e; iii) lacunas no conhecimento sobre reais necessidades dos consumidores mundiais. Para as micros e pequenas empresas (MPEs), a utilização do Drawback, apesar de ter reduzido custos e possibilitado a aquisição de insumos com melhor qualidade, não proporcionou competitividade nas exportações, bem como não aumentou as vendas. Segundo esses autores, seria necessário que as autoridades responsáveis promovessem soluções para essas empresas, como consórcios de exportações entre firmas do mesmo ramo ou de setores complementares e arranjo produtivo local $(\mathrm{APL})$, com o objetivo de exportar e utilizar ações conjuntas de marketing, logística e de negociação no exterior.

\section{Modalidades de Drawback mais Utilizadas pelas Empresas do Estudo}

O Regime Aduaneiro Especial de Drawback na modalidade Integrado Suspensão foi o mais utilizado entre as empresas nos estudos da presente revisão (Bart \& Dörr, 2017; Silva \& Dalfior, 2017; Dallacorte \& Zeni, 2015; Olivo et al., 2015; Moori et al., 2012; Mayer \& Borba, 2006).

Dallacorte e Zeni (2015), avaliaram uma indústria do setor alimentício, que adquire insumos para a produção de aves e suínos sem ter que arcar com os tributos incidentes na operação e transforma o produto em vários tipos de cortes para exportação. Os autores reforçaram que a aquisição dos insumos sob o amparo do Drawback Integrado Suspensão foi, tributariamente, mais rentável que importar ou comprar no mercado interno em condições comuns.

Igualmente, de acordo com Olivo et al. (2015), entre as 13 empresas produtoras exportadoras do sul do estado de Santa Catarina, o Drawback Integrado Suspensão também foi o mais utilizado (84\%). Dessa forma, torna-se possível suspender o pagamento de tributos já a partir dos primeiros passos da importação, com economia de recursos financeiros. Outra observação dos autores foi a baixa utilização do Drawback Verde-amarelo pelas empresas, que possibilitaria a isenção ou a suspensão de tributos sobre a compra de matérias-primas nacionais, o que demonstra maior procura por produtos importados para transformação, na sua maioria, provenientes da Ásia. Ou seja, mesmo com o benefício para a aquisição de matérias-primas no país, em geral, os produtos brasileiros não são competitivos.

Moori et al. (2012) também encontraram resultados semelhantes. Segundo esses autores, a grande maioria $(79,5 \%)$ das empresas utilizavam o Drawback Suspensão e apenas 17,8\% e 2,7\%, relataram utilizar as modalidades Isenção e Restituição, respectivamente. Uma das explicações 
para essas empresas utilizarem a modalidade Suspensão, de acordo com os autores, estaria no fato de que o tipo de produção do setor de máquinas e equipamentos ocorre, em geral, sob encomenda, a qual possibilita o planejamento da cadeia logística de modo integrado.

O estudo de Mayer e Borba (2006), que avaliou 15 empresas moveleiras usuárias do Drawback, também questionou o entendimento e o interesse das mesmas em utilizar esse regime e encontrou que a modalidade Isenção é a menos conhecida das empresas com, aproximadamente, 26,7\% das respostas, seguida do Drawback Restituição (20\%) e do Verde-amarelo (20\%). Já a modalidade Suspensão é conhecida e utilizada por todas as empresas.

Os resultados do estudo de Bart e Dörr (2017) também evidenciam o uso da modalidade Integrado Suspensão pela empresa avaliada, entretanto os autores mencionaram que o melhor caminho para a empresa em questão seria o uso do Drawback Suspensão Genérico, que otimizaria os resultados do negócio da empresa.

\section{Planejamento Estratégico e Logística Integrada para o uso do Drawback}

De acordo com Dallacorte e Zeni (2015), a melhor forma de reduzir a carga tributária, de modo legal, é pelo planejamento tributário. O processo de Drawback deve ser controlado por diversos planejamentos, os quais precisam ser atualizados diariamente para a maior resolutividade possível.

Mayer e Borba (2006), em pesquisa realizada com empresas moveleiras de São Bento do Sul, encontraram que, para melhor aproveitamento do Drawback, seria necessário às empresas que o processo fosse realizado com base em um planejamento estratégico ativo. Esses autores demonstraram que apenas $40 \%$ das empresas consultam sistematicamente fornecedores estrangeiros. Dallacorte e Zeni (2015) reforçaram que, para um planejamento tributário adequado, fazse necessário que o profissional responsável seja um conhecedor da legislação. Todavia, sabe-se que isso é um trabalho difícil no Brasil, pois a legislação é volumosa e complexa, devido ao número expressivo de tributos existentes, bem como às suas frequentes alterações. O papel do gestor, contudo não pode ser limitado à redução da carga tributária, mas em observar também o cumprimento das obrigações fiscais pela empresa. Além disso, os autores concluem que, para o sucesso da importação com o uso do Drawback, é necessário tanto o planejamento, quanto a integração entre os departamentos envolvidos no processo.

O processo logístico de uma organização é complexo, pois envolve uma série de operações que incluem planejamento, alocação e controle de insumos e de produtos. Dentro desse contexto, Moori, Benedetti e Konda (2012) mostraram as principais desvantagens relatadas pelos respondentes da pesquisa como sendo a carência de pessoal com conhecimento especializado no Drawback, seguida da complexidade do regime e dos rígidos controles fiscais necessários para a sua execução. Entretanto, os autores observaram que, após a operação do Drawback ter sido compreendida, as complicações relativas às atividades logísticas para as empresas usuárias do regime diminuíram.

\section{Perfil dos Profissionais Atuantes com o Regime de Drawback nas Empresas}

O estudo de Moori et al. (2012) indicou que as operações com o Drawback eram exercidas, principalmente, por profissionais em cargos de diretoria e gerência $(49,4 \%)$, fato que demonstra a relevância do tema em questão pelas empresas. Da mesma forma, a função mais incidente entre os profissionais que lidam com o regime foi a de exportação e importação (31,5\%). Isso mostra que o conhecimento sobre o Drawback esteve concentrado em profissionais relacionados ao comércio internacional. Esses resultados corroboram com os achados de Silva e Dalfior (2017), os quais mostraram que os profissionais do setor de exportação (54\%) são os principais responsáveis pelas operações com o Drawback na empresa, seguido do setor de contabilidade/fiscal (15\%).

A função mais presente foi a de operações de comércio exterior (62\%), envolvendo exportações e importações.

Moori, Benedetti e Konda (2012), também mostraram resultados semelhantes, mas com menor discrepância em relação aos cargos ocupados pelos profissionais atuantes no regime, uma vez que os cargos de diretoria ou superior representaram $26 \%$ do total. Em relação à função, a mais frequente na amostra também foi a de operações de comércio exterior, com 38\% do total. Santos e Toledo Filho (2005), reforçaram também a importância do 
profissional de controladoria nos processos da empresa, inclusive na gestão do regime de Drawback.

\section{Perfil das Empresas Avaliadas Usuárias do Drawback}

Moori et al. (2012) avaliaram 73 empresas, usuárias do Drawback, do setor de fabricação de bens de capital. 71,2\% estavam localizadas em São Paulo, seguido de Minas Gerais (11\%). No estudo de Moori, Benedetti e Konda (2012), São Paulo também foi o estado que contou com o maior número de empresas (76,5\%). Das 136 empresas da amostra na referida pesquisa, 98 delas eram usuárias do Drawback e, entre estas, 94,9\% eram do ramo de bens de capital. Moori, Konda e Gardesani (2011), também encontraram uma porcentagem alta de empresas usuárias do regime, pertencentes ao setor de bens de capital (94,9\%), seguido do setor de serviços (consultorias) $(4,1 \%)$ e uma empresa $(1,1 \%)$ do ramo de despachante aduaneiro.

Dallacorte e Zeni (2015) analisaram uma empresa alimentícia de Santa Catarina, já Santos e Toledo Filho (2005) pesquisaram uma do ramo das indústrias têxteis, também de Santa Catarina. Os resultados dos dois estudos mostraram que o Drawback foi um estímulo às exportações dessas organizações pela desoneração tributária e consequente redução dos custos de operacionalização que o regime acarreta. Além disso, esse regime propiciou o crescimento e o fortalecimento no mercado internacional e melhorou a competitividade dos produtos.

Quanto ao tamanho da empresa, Moori et al. (2012) evidenciaram, em sua pesquisa, que a maior parte das usuárias do Drawback eram as médias e grandes empresas (MGEs) (68,5\%) e que apenas 23 usuárias eram MPEs. Contudo, no estudo de Moori, Benedetti e Konda (2012) houve homogeneidade entre as pequenas, médias e grandes empresas, as quais representaram $31,5 \%$ do total cada uma, enquanto que as microempresas, em média, representaram uma porcentagem menor (5,5\%) do total das empresas avaliadas. Moori, Konda e Gardesani (2011) encontraram 29 empresas (29,5\%) como MPEs, 32,7\% médias e 37,85 grandes. Outro dado relatado foi o pouco tempo de experiência com o Drawback pelas firmas. Evidenciou-se que 37,8\% das empresas utilizaram o regime entre cinco e dez anos e $27,6 \%$ por menos de cinco anos.

Silva e Dalfior (2017) observaram que as empresas de rochas ornamentais avaliadas em sua pesquisa, usuárias do regime especial de Drawback, foram as de maior porte, com melhor estrutura, mais tempo no mercado e com clientela considerável no mercado externo. Quanto ao tempo de uso do regime, 69\% relataram mais de sete anos e as restantes começaram a utilizar o benefício há menos tempo.

O estudo de Olivo et al. (2015), realizado com 44 companhias exportadoras do sul de Santa Catarina (13 usuárias e 31 não usuárias do Drawback), que importavam matérias-primas e exportavam seus produtos, mostrou que a experiência relatada com o uso do regime foi também, em média, de no máximo dez anos. Além disso, pelo tipo de matéria prima que mais comumente essas empresas importam, constatou-se que a maioria delas era do ramo de cerâmica e química. Esse tipo de companhia utiliza produtos químicos especiais, os quais são mais caros e de menor qualidade no Brasil, o que reforça a necessidade de aquisição desses produtos via importação.

\section{Importação e Exportação com o Drawback}

Moori, Benedetti e Konda (2012) demonstraram que $87,5 \%$ das empresas avaliadas utilizaram insumos importados, porém apenas 82,3\% delas informaram usar o regime de Drawback. Ou seja, 21 das 119 empresas que importaram insumos não utilizaram o Drawback e dentre as usuárias do regime, a maioria $(70,5 \%)$ era de médio ou grande porte. Os autores relataram também, quanto à participação da exportação no faturamento anual, que apenas $2 \%$ das empresas tinham nas exportações uma representatividade acima de $75 \%$ do faturamento anual. Nesse quesito, Moori, Konda e Gardesani (2011), mostraram que a maioria (71,3\%) das empresas de seu estudo obteve pouca representatividade das exportações no total de seu faturamento.

Olivo et al. (2015) encontraram que a frequência de importação nas empresas usuárias do regime ocorreu de forma esporádica, com compras concentradas em poucas datas no ano e com um volume maior de matérias primas por lote de importação. Ao contrário, a exportação ocorreu, mais em geral, em intervalo semanal. Contudo, algumas empresas também exportavam esporadicamente seus produtos sob o Drawback e grande parte dessas matérias-primas eram provenientes da Ásia e Europa. A América do Sul foi o continente que mais se destacou como destino dos produtos finalizados sob as operações com o Drawback. 


\section{Vantagens, Desvantagens e Justificativas do Uso ou não do Drawback pelas Empresas}

As vantagens e a gestão adquiridas com a utilização do Drawback são percebidas de forma diferente pelos gestores conforme o porte das empresas. Para as MPEs, o uso do regime permitiu a diminuição dos custos e a aquisição de insumos de melhor qualidade, mas não aumentou a competitividade nas exportações, nem as vendas ao exterior. Já no caso das MGEs, o Drawback influenciou mais positivamente nas exportações e possibilitou mais competitividade e desenvolvimento de novos produtos com insumos importados (Moori, Konda \& Gardesani, 2011). Da mesma forma, para Santos e Toledo Filho (2005), o Drawback também permitiu que a empresa estudada oferecesse seus produtos a preços mais competitivos no mercado internacional.

Dallacorte e Zeni (2015) consideram também que o sucesso do Drawback nas operações de importação está diretamente associado ao planejamento e à integração entre os setores envolvidos no processo, com destaque aos de exportação e produção. Adicionalmente, Moori et al. (2012) encontraram em seu estudo que, em relação às MPEs, a influência do Drawback ocorre principalmente na etapa de suprimentos e nas importações de insumos ou de matéria-prima, com foco na qualidade e nos custos. Já nas MGEs, essa influência ocorre mais nas etapas de apoio à manufatura e de exportação com ênfase na produção, na expansão de mercados estrangeiros e de clientes e em margens de contribuição. Já as MGEs apresentam maior capacidade em inserir novos produtos no mercado externo, quando comparadas às de médio e pequeno porte.

No estudo de Moori, Benedetti e konda (2012), os principais pré-requisitos indicados pelos respondentes da pesquisa para a utilização do Drawback, foram a capacitação gerencial e o conhecimento especializado. Evidencia-se que, para esses profissionais, os benefícios que o regime propicia à empresa estão condicionados à melhoria operacional e à gerencia dos recursos humanos envolvidos na operação. Dessa forma, de acordo com o referido estudo, a maior desvantagem da utilização do Drawback foi a dificuldade de se obter profissionais com conhecimento especializado para operar o regime, seguido da complexidade da operação e a necessidade de rígidos controles tributários, da necessidade de rigor no controle fiscal e dos processos de produção e armazenagem.

Brito Jr. et al. (2012) analisaram o impacto de dois regimes aduaneiros, o Drawback e o Recof, em empresa fabricante de aviões, onde o Drawback está sendo substituído pelo Recof Aeronáutico. Os autores observaram que além de proporcionar ganhos com a redução dos custos logísticos, o Recof promoveu mais vantagens na estratégia competitiva dos usuários, com redução dos ciclos logísticos e dos lead times de abastecimento do que o Drawback, com mais flexibilidade nas linhas de produção e maior capacidade de atendimento às solicitações dos clientes.

Conforme Moori, Konda e Gardesani (2011), para as MPEs usuárias do Drawback, a qualidade dos insumos importados foi referida como uma das principais vantagens em se utilizar o regime. Já para as MGEs, o Drawback aumenta a participação da empresa no mercado internacional e o número de vagas de emprego. A não utilização do regime por $41,3 \%$ do total das MPEs não fez com que as mesmas se sentissem excluídas das demais em atividades de encontros de classe. Além disso, $84,1 \%$ dos respondentes concordaram que o Drawback atende às necessidades da empresa.

Os autores reforçam ainda que, no caso das MGE, o regime de Drawback influenciou mais sobre o rigoroso controle nos processos de produção e armazenagem, os quais são realizados através de programas de computação específicos. A falta de flexibilidade nas normas também foi citada por grande parte dos respondentes como fator negativo ao uso do regime, sobretudo em relação à inadimplência ou aos prazos de prorrogação do ato concessório.

Entre as empresas que não utilizavam o Drawback, Moori, Benedetti e Konda (2012) listaram que as principais dificuldades para o uso do regime foram a capacitação gerencial, o conhecimento, o controle fiscal e, em última análise, o controle dos processos de produção e armazenagem. Ou seja, o estudo demonstrou que as empresas não usuárias precisam de capacitação para adotar o regime. Ainda foram pontuados a morosidade e a burocracia para aprovação do ato concessório, além da dificuldade de compreensão das leis e das regras que envolvem o processo aduaneiro do regime, pelas empresas não usuárias, como obstáculos o Drawback. 
Dallacorte e Zeni (2015) mostraram que a aquisição de matéria-prima sob amparo do Drawback foi mais viável, tributariamente, do que importar ou comprar no mercado interno sob condição comum. Foi possível também reduzir o custo da produção, melhorar o fluxo de caixa, reduzir o custo das obrigações tributárias e do produto final a ser exportado. O produto acabado tornou-se mais competitivo no comércio internacional, com consequente incremento nas exportações, justificando-se, assim, a importância para a empresa em questão na aquisição de insumos amparados pelo regime.

Silva e Dalfior (2017) avaliaram 21 empresas do ramo de rochas ornamentais Espírito Santo, 13 (62\%) delas eram usuárias e oito (38\%) não usuárias do Drawback. Os investigadores concluíram que se beneficiavam do regime aduaneiro as empresas maiores, melhores estruturadas, com mais tempo no mercado e maior cartela de clientes no mercado externo. Apesar de 38\% das empresas não utilizarem o Drawback, por falta de conhecimento sobre o processo, as mesmas responderam que tinham interesse em compreendê-lo e utilizá-lo.

\section{DISCUSSÃO}

Nações em desenvolvimento, como o Brasil, encontram múltiplas dificuldades para solucionar os problemas que afligem a população e que impedem o crescimento econômico, como o desemprego e a pobreza. Nesse sentido, estímulos às exportações, como o Drawback, podem contribuir para o desenvolvimento sustentável, pelo consequente aumento da produção nacional, do emprego e da renda (Mota \& Amaral, 2013).

A partir da avaliação dos dez artigos originais, apresentados na sessão dos resultados, a presente pesquisa buscou demonstrar as vantagens e as desvantagens do uso do Drawback e sua importância como mecanismo para redução de custos nas exportações e de favorecimento à internacionalização de empresas brasileiras. Os resultados mostraram que o Drawback foi considerado pelas empresas um importante instrumento na logística do comércio internacional em função dos incentivos fiscais e da redução dos custos da produção. Empresas maiores conseguiram vantagens competitivas e aumentaram suas vendas com o Drawback, entretanto o nível de internacionalização das empresas foi baixo, mais notadamente entre as de menor porte.
De acordo com Prozczinski e Steinbruch (2014), empresas menores sofrem com despreparo e falta de recursos para a conquista do mercado externo. Calof (1994) reforça que, independentemente do porte, outros obstáculos à internacionalização de uma empresa são a burocracia, os processos internos e a complexa carga tributária. São necessárias políticas públicas voltadas para inserção competitiva das empresas no mercado externo, de maneira que o país possa se diferenciar internacionalmente como grande exportador e crescer, de forma sustentável. Tais políticas devem pautar-se em garantir incentivos governamentais de melhoria em tecnologia, bem como de gestão (Wright \& Giovinazzo, 2004).

Segundo Bowersox \& Closs (2008), no comércio internacional, para que uma empresa seja bemsucedida, a mesma precisa enfrentar diversos desafios, como estoque, idioma, transporte, coordenação/integração das operações e formação de alianças com terceiros. Assim, uma empresa exportadora, além de compreender e planejar estrategicamente o processo do Drawback, necessita de um conjunto de estratégias que envolvam recursos e capacidades administrativas, avaliação de necessidade de investimento em recursos humanos e materiais, estoques, assumir riscos e grau de controle sobre os processos relativos ao negócio (Lima, 2006).

A presente pesquisa evidenciou como principais desvantagens para a operação com o Drawback, a carência de pessoal com conhecimento especializado, seguida da complexidade do regime e dos rígidos controles fiscais necessários para a sua execução. Entretanto, observou-se que, após a operação ter sido compreendida, as complicações relativas às atividades logísticas para as empresas usuárias do regime diminuem.

Esta pesquisa revelou também que a modalidade mais utilizada pelas empresas brasileiras foi o Drawback Integrado Suspensão. Esse benefício é um regime aduaneiro especial que suspende os tributos incidentes nas importações ou nas aquisições no mercado interno sobre insumos a serem usados como matéria-prima de produtos a serem obrigatoriamente exportados (MDIC, 2011).

Um dos artigos incluídos nesta revisão avaliou o Drawback e o Recof numa empresa de fabricação de aeronaves. Desde 2006, observou-se uma transição parcial do Drawback para Recof. Já em 2009, o Recof foi o que mais possibilitou a suspensão de tributos nas importações da empresa (Brito Jr. et al. 2012). 
Contudo, o Recof pode ser utilizado apenas por um limitadíssimo número de empresas de grandes segmentos, tais como os setores aeronáutico e automotivo. Já o Drawback permite a suspensão em todos os setores da economia (básico, intermediário e industrializado), independente do porte (Barral \& Sá Barreto, 2010), como observado na presente pesquisa.

No presente estudo, observou-se que, para as operações com o Drawback, em geral (62\%), as empresas utilizam profissionais com conhecimento em operações de comércio exterior, envolvendo exportações e importações. Timo (2010), considera que é necessário um planejamento efetivo para que se consiga atender às regras que regem o comércio internacional, considerando as importações, que podem aumentar os preços dos tributos, além de multa e juros aos custos por desconhecimentos das partes, inclusive no regime de Drawback. O que reforça a necessidade de profissionais com conhecimento especializado nas operações com esse regime aduaneiro.

Quando comparados os dados do Portal Sixcomex - RFB/SECEX, mostrado na Tabela 1 , relativos à participação do regime de Drawback entre as exportações brasileiras nos últimos 12 anos, observou-se que no período entre 2005 a 2007, a porcentagem de uso do Drawback alcançou médias superiores a $30 \%$ no total das exportações. Entretanto, a partir desse período houve uma diminuição da participação do regime nas exportações totais. De acordo com Silva (2014), uma das explicações é que, apesar de o Drawback não ter restrições de acesso em razão do porte das empresas, o mecanismo não tem conseguido alcançar empresas menores. Ao contrário, tem sido mais utilizado por grandes exportadores, com receita anual de vendas ao exterior superiores a US\$1 milhão.

Quanto ao uso do Drawback, elencou-se como principais vantagens pelas usuárias, para as MPEs: i) a redução dos custos e ii) a aquisição de insumos de melhor qualidade. Já para as MGEs foram: i) a redução dos custos; ii) o aumento da competitividade; iii) o desenvolvimento de novos produtos com insumos importados; iv) o aumento da participação da empresa no mercado internacional e; v) o aumento do número de vagas de emprego. Barney e Hesterly (2011), também encontraram que - Drawback é um mecanismo que permitiu a aquisição de matérias-primas de melhor qualidade, com tecnologia mais avançada a preços menores que no mercado interno.

Para Cuba, Coti-Zelati e Araújo (2014), o benefício, proporciona vantagem competitiva para a internacionalização de empresas pela diminuição dos custos da produção e por facilitar seu acesso no mercado externo, o que foi comprovado no presente trabalho no caso das MGEs. Todavia, no caso das MPEs, mesmo tendo reduzido custos e permitido aquisição de insumos de melhor qualidade, o incentivo não proporcionou maior competitividade, nem aumentou as vendas no mercado internacional. Os autores observaram como desvantagens sobre a utilização do Drawback: i) a dificuldade de se obter profissionais com conhecimento especializado; ii) a complexidade da operação; iii) a necessidade de rígidos controles tributários e fiscais; iv) o rigor no controle dos processos de produção e armazenagem e; v) a falta de flexibilidade nas normas, sobretudo quanto à inadimplência ou prazos de prorrogação do ato concessório.

Entre as firmas não usuárias do Drawback as principais dificuldades para a utilização foram: i) a falta de conhecimento sobre o processo; ii) a necessidade de capacitação gerencial; iii) o controle fiscal e dos processos de produção e armazenagem; iv) a morosidade do processo; v) a burocracia para aprovação do ato concessório e; vi) a dificuldade de compreensão das leis e das regras que envolvem o processo aduaneiro do regime. $\mathrm{O}$ estudo apontou que as empresas não usuárias têm interesse em utilizar o benefício (Cuba, Coti-Zelati \& Araújo, 2014).

Todas as desvantagens listadas por Araújo e Sartori (2003) no referencial teórico desta revisão também foram reforçadas pelos respondentes das pesquisas avaliadas no presente estudo, mas cabe aqui destacar a importância do último item referido por esses autores, no que diz respeito às políticas públicas desiguais, como a falta de uma regulamentação específica à pequenas e médias empresas.

\section{Limitações do Estudo}

Apesar de o Drawback ser um assunto importante para o comércio internacional, foram encontrados poucos estudos disponíveis on-line sobre o tema, o que pode ser considerado um fator limitante desta revisão. Outra limitação encontrada foi o fato de que os dez artigos originais analisados nos resultados foram realizados com empresas situadas nas regiões 
Sudeste e Sul do Brasil, o que pode não corresponder à realidade de outras empresas situadas nas demais regiões do país.

\section{CONSIDERAÇÕES FINAIS}

Esta pesquisa questionou a importância do regime aduaneiro de Drawback para a prática de internacionalização de empresas brasileiras e quais fatores têm influenciado essas organizações a aderirem, ou não, a esse regime. Em resposta à esta questão, os dados encontrados mostraram que o uso do Drawback, no que diz respeito à redução dos custos pela desoneração de tributos incidentes na operação, é vantajoso financeiramente para as empresas que atuam ou almejam investir no mercado internacional. Contudo, devido ao processo burocrático do sistema aduaneiro à carência de pessoal capacitado para a sua operacionalização, os benefícios desse regime não têm estimulado uma parcela significativa de empresas brasileiras, independentemente do porte, à sua adesão.

Várias são as vantagens advinda do Drawback, dentre elas destacou-se, neste estudo, a qualidade dos insumos importados e a redução dos custos para as MPEs e a melhoria da eficiência produtiva, a expansão de novos mercados e clientes internacionais, bem como o aumento do faturamento, da competitividade e das vendas para as MGEs. No entanto, o estudo mostrou que mesmo em relação às usuárias, o baixo nível de internacionalização ainda ocorre e é mais acentuado quanto menor o tamanho da empresa.

Assim, são necessários investimentos em políticas públicas de incentivo ao comércio internacional que facilitem a adesão das empresas brasileiras ao regime de Drawback, como uma regulamentação que descomplique o acesso e o cumprimento dos trâmites burocráticos do processo. Tais políticas devem estimular empresas e profissionais que buscam aumentar a competitividade no mercado internacional a investirem na capacitação gerencial para atuação com o Drawback. Foi observada também a necessidade de revisão da atual legislação no que diz respeito aos custos administrativos e tributários do regime, à lentidão dos processos burocráticos e à ausência de regulamentação destinada especificamente às empresas menor porte. Outra solução seria a constituição de consórcios de exportação, pactuados entre empresas de setores comuns de atividades.

Diante da crise econômica e política vigente no país, o presente estudo trata de um tema relevante. Os resultados poderão nortear empresas que almejam a internacionalização de seus negócios na tomada de decisão quanto ao uso dessa ferramenta de apoio à exportação.

Esta pesquisa, realizada de acordo com o rigor de um método validado cientificamente, a Revisão Integrativa da Literatura, permitiu elencar e agrupar evidências científicas sobre o Drawback, um regime aduaneiro especial de incentivo às exportações e sua importância para a internacionalização de empresas localizadas no território brasileiro. Os achados desta revisão, portanto, concentram uma fonte de consulta para pesquisadores da área que se interessarem pelo aprofundamento do assunto, devido sua importância para a economia e o crescimento do país. Portanto, mais estudos são necessários, principalmente nas regiões Centro Oeste, Norte e Nordeste do Brasil, onde detectou-se uma carência de publicações de estudos locais e primários sobre o tema.

A partir dos resultados desta revisão, como sugestões para pesquisas futuras sobre o tema, identificou-se algumas possíveis extensões: i) investigar, no caso das MPEs, porque o uso do Drawback, apesar de ter permitido a redução dos custos e a aquisição de insumos de melhor qualidade, não aumentou a competitividade dessas empresas, nem as vendas no mercado internacional; ii) avaliar o impacto da capacitação gerencial para a operacionalização com o Drawback no desempenho internacional das empresas exportadoras, inclusive daquelas iniciantes que aspiram novos mercados e clientes no comércio exterior e, por fim iii) realizar um levantamento de como as políticas públicas de incentivo acerca dos regimes aduaneiros especiais como o Drawback têm sido trabalhadas no Brasil pelos órgãos competentes e como as empresas têm lidado com a questão. 


\section{REFERÊNCIAS}

Araújo, A. C. M. S. \& Sartori, A. (2003). Drawback e o comércio exterior: Visão jurídica e operacional. São Paulo: Aduaneiras.

Barney, J. B. \& Hesterly, W.S. (2011). Administração estratégica e vantagem competitiva (3a ed.). São Paulo: Pearson.

Barral, W. \& Sá Barreto, A. (2010). Desoneração tributária e o regime de Drawback. Revista Brasileira de Comércio Exterior (RBCE), 102 (1), 50-58.

Bart, R. C. \& Dörr, H. A. (2017). Estudo de caso nas operações sob o regime em uma empresa do município de Igrejinha/RS. Revista Eletrônica de Ciências Contábeis, 6 (1), 141-166.

Brito Jr., I., Belfiore, P. \& Yoshizaki, H. T. Y. (2012). Um modelo de localização e transbordo multiproduto para avaliação do impacto de regimes aduaneiros. Transportes, 20 (3), 89-90.

Bowersox, D. J. \& Closs, D. J. (2008). Logística empresarial: o processo de integração da cadeia de suprimento. (6a reimpressão). São Paulo: Atlas.

Calof, J. L. (1994). The Relationship between Firm Size and Export Behavior Reviseted. Journal of International Business, Studies, 25 (2), 367-387.

Cuba, P. C.; Coti-Zelati, P. E. \& Araújo, D. L. A. (2014, novembro). O regime aduaneiro de Drawback como estratégia competitiva: Um estudo sobre a indústria metalúrgica do Grande $A B C$. Anais do XI Congresso virtual brasileiro de Administração, CONVIBRA, São Paulo, SP, Brasil, 11. Recuperado em 23 abril, 2017, de http://www.convibra.com.br/upload/paper/2014/32/2 014_32_9556.pdf

Dallacorte, F. \& Zeni, V. L. F. (2015). Utilização do regime Drawback como fator competitivo no mercado internacional. Revista Tecnológica, 3 (2), 197-210.

Decreto-Lei n. 37, de 18 de novembro de 1966. (1966). Dispõe sobre o imposto de importação, reorganiza os serviços aduaneiros e dá outras providências. Recuperado em 11 abril, 2017, de http://www2.camara.leg.br/legin/fed/declei/19601969/decreto-lei-37-18-novembro-1966-375637normaatualizada-pe.pdf

Folloni, A. P. (2005). Tributação sobre o comércio exterior. (1a ed.). São Paulo: Dialética.

Freitas, L. A (2004). Importância da eficiência logística para o posicionamento competitivo das empresas no mercado internacional. In VIII Encontro Latino Americano de Iniciação Científica e IV Encontro Latino Americano de Pós-Graduação, Anais dos trabalhos 2004 (p. 748-752). Vale do Paraíba: Autor. Recuperado em 20 março, 2017, de http://www.inicepg.univap.br/cd/INIC_2004/trabalhos /inic/pdf/IC6-45R.pdf

Guimarães, C. A. A. (2015). Contribuição do Drawback para a estratégia de internacionalização em uma empresa do setor automobilístico (Dissertação de Mestrado). Faculdade Pedro Leopoldo, Pedro Leopoldo, Minas Gerais, MG, Brasil.

Ikeda, D. (2016). Constituição do Crédito Tributário no Drawback. Âmbito Jurídico, 19 (146). Recuperado em 15 março, 2017, de http://www.ambito-

juridico.com.br/site/?n link=revista artigos leitura \&artigo id=16974\&revista caderno=26

Lima, M. (2006). Marketing internacional. In: VASCONCELLOS, M. A. S., Lima, M. \& Silber, S. Gestão de negócios internacionais. São Paulo: Saraiva, 195229.

Mayer, B. M. Z. F. \& Borba, J. A. (2006). Influência do Drawback no preço de exportação do setor moveleiro de São Bento do Sul. In XXIV Simpósio de Gestão de Inovação Tecnológica - ANPAD, Anais dos trabalhos 2006. Gramado, RS.

Mendes, K. D. S., Silveira, R. C. C. P. \& Galvão, C. M. (2008). Revisão Integrativa: Método de pesquisa para a incorporação de evidências na saúde e na Enfermagem. Texto \& Contexto Enfermagem, 17 (4), 758-64.

Ministério do Desenvolvimento, Indústria e Comércio Exterior, MDIC. (2011). Cartilha do Drawback Integrado. Brasil: Autor. Recuperado em 16 março, 2017, de http://www.mdic.gov.br/arquivos/dwnl_131119674 3.pdf

Moori, R. G., Benedetti, M. H. \& Konda, S.T. (2012). O regime aduaneiro de Drawback em operações logísticas internacionais. Pretexto, 13 (1), 114-133.

Moori, R. G., Konda, S. T., Farias, O. O. \& Moori, T. M. (2012). A influência do Drawback nas atividades logísticas em empresas de bens de capital mecânico. Revista de Administração e Inovação, 9 (4), 68-95.

Moori, R. G., Konda, S. T. \& Gardesani, R. (2011). Regime aduaneiro do Drawback em empresas de 
bens de capital. Gestão \& Regionalidade, 27 (80), 8596.

Mota, A. \& Amaral, C. S. (2013). Fomento ao desenvolvimento econômico a partir da possibilidade dos incentivos à exportação através do regime aduaneiro especial - Drawback. Revista Videre. 5 (9), 52-66.

Olivo, S., Zilli, J. C.; Gianezini, M. \& Yamaguchi, C. K. (2015). Logistics and special customs regimes: The uses of Drawback by export companies in southern Brazil. Business Management Dynamics, 5 (6), 1-12.

Prozczinski, D. \& Steinbruch, A. M. (2014). Os Obstáculos à internacionalização de empresas inovadoras e o papel dos Ambientes de Inovação no Brasil. In XXIV Seminário Nacional de Parques Tecnológicos e Incubadoras de Empresas; XXII Worshop - Anprotec, Belém, Pará, Brasil. Recuperado em 05 março, 2018, de http://www.anprotec.org.br/Relata/ArtigosCompletos/ ID\%2036.pdf

Santos, C. C. \& Toledo Filho, J. R. de. (2005). Contribuição da controladoria no comércio exterior para otimização de resultados em operações internacionais: Um estudo de caso. Revista Universo Contábil, 1 (1), 41-53.

Silva, L. G. \& Dalfior, M. D. (2017). Drawback: Estudo de controles de utilização em empresas de rochas ornamentais no Sul do Estado do Espírito Santo. Revista Científica da Faccaci, 2 (1), 37-53.

Silva, R. A. (2014). O regime de Drawback e sua contribuição para as exportações dos setores industriais brasileiros (Dissertação de Mestrado). Universidade de Brasília, Brasília, DF, Brasil.

Timo, L. R. (2010). Drawback Suspensão Integrado: implantação e redução de custos nas importações de matéria-prima de empresa exportadora. (Dissertação de Mestrado). Escola Brasileira de Administração Pública, Rio de Janeiro, RJ, Brasil.

Whittermore, R. \& Knafl, K. (2005). The integrative review: Updated methodology. Journal of Advanced Nursing, 52 (5), 546-553.

Wright, J. T \& Giovinazzo, R. A. (2004). A Política Industrial e a Estratégia da Nação. In Política Industrial 2. São Paulo: Publifolha.

\section{SOBRE OS AUTORES}

- Christiane Nery Silva Pirett - Mestranda em Administração pela Universidade Federal de Uberlândia - UFU, Minas Gerais, (Brasil). E-mail: chris.nery@gmail.com Orcid id: https://orcid.org/0000-0003-0300-9687

- Cely Cristiane Nery Silva Pirett - Mestra em Ciências da Saúde com Ênfase em Epidemiologia/Infecção Hospitalar pela Universidade Federal de Uberlândia - UFU, Minas Gerais, (Brasil). E-mail: celpirett@yahoo.com.br Orcid id: https://orcid.org/0000-0002-5169-823X

- Luciana Oranges Cezarino - Doutora em Administração pela Universidade de São Paulo - USP, São Paulo (Brasil) e Pós-doutora em Engenharia pela Politecnico di Milani - POLIMI, (Itália). E-mail: Icezarino@gmail.com Orcid id: https://orcid.org/0000-0001-5556-8275 
THE IMPORTANCE OF THE DRAWBACK CUSTOMS REGIME FOR INTERNATIONALIZATION OF BRAZILIAN COMPANIES

\author{
Christiane Nery Silva Pirett, Cely Cristiane Nery Silva Pirett, Luciana Oranges Cezarino \\ Universidade Federal de Uberlândia, Minas Gerais, (Brazil)
}

ARTICLE DETAILS
Article history:
Received: 21 april 2018
Accepted: 10 september 2018
Available online January: 01th 2019
Double Blind Review System
Scientifc Editor
Ilan Avrichir

\section{Keywords:}

Drawback Customs Regime

Globalization

Exportation

Internationalization of companies

\begin{abstract}
The aim of this study was to seek scientific evidences about the positive and negative aspects that have led Brazilian companies to establish or not the customs regime of Drawback. It is an Integrative Review of literature, with systematic content analysis, conducted between March-April/2017. Primary studies published between 2005 and 2017, on-line and in full text format and data from the Foreign Trade Secretariat portal of the Ministry of Development and Industry and Commerce were included. The results showed that although Drawback effectively reduces the tax burden of export inputs, there was no increase in the regime's use rates in relation to total Brazilian exports in recent years. Even among the Drawback users, most companies exported with a high index of nationalization, without the benefits of the regime. Due to the excessive bureaucracy of the customs system and the lack of personnel capable of operationalizing it, the benefits of Drawback although relevant - such as cost reduction, expansion of foreign markets and improvement of production efficiency - did not encourage significant Brazilian companies to join Drawback. Therefore, it is necessary political investments of incentive to international trade, as managerial qualification for its operation, to stimulate Brazilian companies to adopt the Drawback regime.
\end{abstract}

Para citar este artigo:

Nery Silva Pirett, C., Nery Silva Pirett, C., \& Oranges Cezarino, L. (2019). A Importância do Regime Aduaneiro de Drawback para Internacionalização de Empresas Brasileiras. Revista Eletrônica de Negócios Internacionais, 14(1), 59-75. doi:https://doi.org/10.18568/internext.v14i1.456 